\title{
El leprosario de José Revueltas
}

\section{The Leper Colony, by José Revueltas}

\author{
José Martínez Torres ${ }^{1}$ \\ Universidad Autónoma de Chiapas. Tuxtla Gutiérrez, México \\ martinez_torres55@hotmail.com \\ ORCID 0000-0001-9936-3829
}

Citar como: Martínez, J. (2019). El leprosario de José Revueltas. Desde el Sur, 11(2), pp. 33-40.

\section{RESUMEN}

Este artículo se enfoca en analizar ciertos aspectos técnicos de lo que José Revueltas denominó «realismo dialéctico-materialista», que consistía en mostrar las escenas y los personajes de mayor crudeza de la sociedad desde la perspectiva de un militante comunista. Esta poética la expuso en un breve ensayo que aparece como prefacio de la edición de 1961 de Los muros de agua y que el autor consideraba el aniversario número veinte de su carrera de escritor, ya que este, su primer libro, había aparecido en 1941. Se ejemplifican los principios literarios aludidos con algunos pasajes de la misma novela y se aprovecha una idea de Virginia Woolf a propósito de la enfermedad en la literatura.

\section{PALABRAS CLAVE}

José Revueltas, realismo dialéctico-materialista, Los muros de agua, enfermedad

\footnotetext{
1 José Martínez Torres estudió letras en la Universidad Nacional Autónoma de México y en la Universidad Complutense de Madrid. Ha recibido distintos premios y distinciones literarios, como la beca del Centro Mexicano de Escritores y el Premio Nacional Rosario Castellanos de Novela Breve. Es profesor de Literatura Mexicana en la Universidad Autónoma de Chiapas. Ha rescatado y editado documentos históricos del siglo XX. Es autor de varios libros de crítica y de prosa narrativa, así como de un número considerable de artículos, reseñas, prólogos, tesis y antologías. Edita Crates. Revista de estudios literarios y forma parte de la mesa de redacción de la revista Artificio. Pertenece al Sistema Nacional de Investigadores.
} 


\section{ABSTRACT}

This article offers an analysis of several technical features of what José Revueltas called dialectical-materialist realism, which involves the depiction of the bleakest scenes and characters of capitalistic society, from the perspective of a militant communist. The author addressed his poetics in a brief essay published as the preface to the second edition of Los muros de agua, which the author saw as marking his twentieth anniversary as a writer whose first work had been published in 1941. The literary principles discussed are illustrated with quotes from the novel in question, while employing Virginia Woolf's own notions associated with disease in literature.

\section{KEYWORDS}

José Revueltas, dialectical-materialist realism, Los muros de agua, disease

En marzo de 1961, José Revueltas cumplió 20 años de escritor; para celebrarlo, se hizo la segunda edición de su primer libro, que incluía una suerte de prólogo titulado "A propósito de Los muros de agua» (Revueltas, 1979, p. 7). Aquí menciona que tenía en mente llevarlo a su hermano mayor, el célebre compositor Silvestre Revueltas: «Yo contaba, al terminar de escribir mi libro, con acudir inmediatamente a leérselo, pues él era un juez implacable y magnífico» (p. 7). Silvestre estaba muy enfermo para entonces, murió y no fue posible entregarle el manuscrito, de manera que nadie leyó la novela hasta que se publicó, al año siguiente, en una edición financiada por su familia.

«A propósito de Los muros de agua» es un documento en el que se exponen asuntos de técnica literaria, preferentemente del realismo, los que Revueltas modificó para establecer su Realismo dialéctico-materialista, una poética con la que aspiraba a lograr una narrativa que fundiría su labor como escritor con su labor como militante comunista. De este modo rompería con las limitaciones de la literatura mexicana y rompería también los moldes sociales que dificultan el desarrollo humano: «es a lo que tiende mi actividad de militante marxista-leninista» (Revueltas, 1979, p. 23).

Para ilustrar estos aspectos teóricos, transcribe una carta dirigida a su esposa acerca de la visita que hizo, junto con el escritor Ramón Rubín, a la casa para leprosos de Guadalajara, en el occidente de México, en 1955. Llama la atención que en este prólogo apenas mencione los pormenores de sus dos estancias en el penal de las islas Marías —en 1932 y en 1934-, 
el tema de la novela, y que en cambio enfatice principios naturalistas, como aquel donde Dostoievski afirma que la realidad siempre resulta más fantástica que la literatura, junto con imágenes, descripciones y testimonios de la atroz enfermedad.

Los leprosarios y los presidios son sitios infernales aún más terribles de lo que puede mostrar la escritura, pues siempre existe en la literatura el peligro de no ser creído: con frecuencia, el escritor no logra «demostrar que aquello [que expone] sea tan espantosamente cierto» (Revueltas, 1979, p. 9). En seguida hace diversas analogías entre los monstruos enfermos de aquel recinto y reflexiona sobre la dificultad de expresar aquello que rebasa lo verosímil.

En estas páginas preliminares, no quiso referirse a los pormenores de Los muros de agua, ya que al avanzar en la lectura se verá la vida infernal de aquellas islas a través de una prosa en la que abundan comparaciones y metáforas de gran exactitud, desde el título del libro, Los muros de agua: reclusión insalvable donde habitan presos políticos y presos del orden común recluidos en una prisión rodeada de agua por todas partes. Como emblema de esta cárcel de muros sin límites está el personaje que entrena arduamente para escapar de la isla a nado, pero tras lograr una condición física extraordinaria, al primer intento es destrozado por los tiburones.

En las reflexiones sobre su novela, escritas 20 años después, dice de los enfermos de lepra: «Yo había contemplado una realidad. Pero dudo que esa realidad pudiese ser transformada en una ficción literaria convincente. Era excesiva, superabundante» (Revueltas, 1979, p. 20). Esta realidad puede llevar al escritor a un realismo malentendido, espontáneo, que por fuerza se desvía hacia el reportaje, hacia el documental, mientras que el espejo realista de Stendhal enseña que «La realidad necesariamente debe ser ordenada, discriminada, armonizada dentro de una composición sometida a determinados requisitos» (Revueltas, 1979, p. 20).

Este prólogo de 1961 es una fuente de primera mano que esclarece los principios técnicos y teóricos de la narrativa de José Revueltas. En menos de 20 páginas explica la clase de realismo que buscaba: «Los muros de agua no son un reflejo directo, inmediato de la realidad. Son una realidad literaria, una realidad imaginada» (Revueltas, 1979, pp. 8-9), y añade que el escritor organiza en sucesiones de palabras lo que ha visto; depende de la realidad que ha vivido, pero debe organizarla; depende de la «realidad de la experiencia» joyceana, pero requiere de un pacto con la composición, a fin de lograr la comprensión del lector. Este ordenamiento y estructura constituyen un problema, ya que «la realidad literalmente tomada no siempre es verosímil, o peor, casi nunca es verosímil» (Revueltas, 1979, 
p. 9). De este modo, el valor primordial del escritor es la verosimilitud: lo vivido siempre rebasará lo que es factible de escribir en un relato.

En una entrevista con David Franco Ávila (2006, p. 29), Revueltas dijo que en sus novelas se daba el lujo de ser todos sus personajes por la sencilla razón de que los había vivido todos: «Me parece muy bien tener una biografía capaz de hacerme personaje de mis novelas» (Revueltas, 1979, p. 29). Se sabe que conoció el penal de las islas Marías aún siendo adolescente y estuvo recluido en todas las cárceles conocidas, desde la Cárcel de Belem hasta el llamado Palacio Negro de Lecunberri; que militó en el Partido Comunista Mexicano y fue expulsado por su postura crítica; que de igual modo lo expulsaron de la Liga Comunista Espartaco, una organización que él mismo había fundado; que viajó a los países del bloque socialista; que se casó y tuvo hijos, no solo en México; que recorrió el país de costa a costa y de frontera a frontera, cumpliendo peligrosas misiones clandestinas; que una debilidad alcohólica lo persiguió hasta su muerte.

Para el autor de Dormir en tierra, un deber del escritor es acumular vivencias, observar la realidad, por cruda y atroz que resulte. Eso es material literario, hay que «ser como un espía de la Divinidad. No se viene a este mundo a ver, sino a transfigurarse [...] de allí que mi literatura resulte un poco agria, escéptica, pero llena de un terrible amor, aun en los peores casos de mi emoción literaria», confesó a David Franco Ávila (2006, p. 29).

Dice en aquel prólogo que la situación de un preso en las islas Marías era incluso peor de lo que alcanza a verse en Los muros de agua. Este asunto se explica porque lo más terrible nunca es evidente: «Lo terrible no es lo que imaginamos como tal: está en lo más sencillo, en lo que tenemos más al alcance de la mano [pero es] incomunicable, [ya que con palabras] no sabemos demostrar que aquello sea espantosamente cierto» (Revueltas, 1979, p. 9).

En esta primera novela de Revueltas se hace énfasis en la vida interior de los personajes; se presentan al lector el pensamiento y las sensaciones, los propósitos, recuerdos y sentimientos de cada uno, exactamente como un espía de Dios. Se trata de un narrador que conoce la vida interior de estos seres dolientes que habitan «un mundo escondidamente monstruoso, subterráneamente anormal y desquiciado» (Revueltas, 1979, p. 77):

El rostro del subteniente Smith era una cosa singular e interesante. En algún sitio [...] lo sorprendió un incendio del cual salió con vida por un verdadero milagro. Sin embargo, su ya pobre y desmedrado cuerpo tuvo que sufrir las consecuencias; quemado en una forma horrible, en su casi totalidad se había contraído mostrando una piel descarnada, brillante, mientras el rostro estaba hecho una plasta escrofulosa (p. 96). 
De otro personaje, el Temblorino, se dice que estaba terriblemente enfermo, pero que no recibía la menor consideración, y en su último día en la montaña, llevando a cabo su trabajo de hachero, había sido abandonado por todos: sufría ataques de epilepsia y solo había quedado un hombre que, al verlo, dejó de trabajar y lo dejó abandonado a su suerte, mientras una mujer fabulosa como el agua en el desierto se aparecía. Era la salud y lo que esta significa. El narrador de Los muros de agua dedica el siguiente párrafo al complejo significado de la salud que solo puede ver un enfermo:

La esplendorosa cualidad de reírse, de gritar, mirando a las mujeres de frente y con desenvoltura. Los hombres sanos eran seguros, altivos: la salud les daba un prestigio vulgar y orgulloso que les hacía poner los pies sobre el suelo como desafiando las cosas más fatales, las más unidas al destino. Pero nadie, en el fondo, podía ser sano. Porque la enfermedad era una noción más próxima a la muerte y por eso más verdadera, y quien contradijera la muerte no podía ser más que un insensato y un iluso. El enfermo no tenía altivez, ni osadía, ni insolencia, por saberse más en contacto con lo trascendental, lo lejano y perdurable, la maldición profunda y vieja que pesaba sobre el hombre. ¡Y pensar que los enfermos debían inclinarse sobre sí mismos y buscar sus goces, sus sueños, sus esperanzas, en los pies y en las rodillas, en el mundo de abajo, mientras los sanos tenían un sólido universo por enfrente, donde las voces eran limpias y los sonidos puros...! (Revueltas, 1979, p. 187).

Veinte años después de escribir Los muros de agua, en este prólogo hace un balance de la diferencia que existe entre los materiales de un escritor y la forma de exponerlos, entre los lugares infernales que llegan a presentarse ante sus ojos y las formas que debe elegir. Durante su visita a los leprosos de Jalisco, se «puso de relieve [...] la frontera que existe entre la realidad y la literatura»: era «el horror en una de sus manifestaciones más desnudas». (Revueltas, 1979, p. 9). El horror que producen los enfermos de lepra «radica en que no son horrorosos de un modo completo, sino apenas. Pálidos, con una palidez que jamás podrá encontrarse en ninguna otra piel humana que no sea la de un leproso; no es blanca, ni mate, ni ambarina esta palidez». (Revueltas, 1979, p. 12). Explica que se trata de un muerto que no está muerto, pero que ya no tiene sangre. Ahora bien, a esto hay que agregar lo mexicano, «sombrero de palma, huaraches, pantalones de dril», y entonces «el conjunto adquiere una dimensión extrañamente realista, simple, natural y pavorosa», concluye. (Revueltas, 1979, p. 12).

Revueltas era capaz de encontrar el amor y la belleza en cualquier parte, incluso en esta casa de los espantos. Se presenta una joven, bella leprosa que sonríe con timidez y candor al médico, pero en cuanto ve a 
los escritores, desaparece la sonrisa y clava la vista en el piso, como si se hubiera deprimido de un momento a otro. Esta joven ha sido contagiada recientemente y su rostro aún expresa sentimientos. "La transición entre su alegría del instante anterior y esta congoja de ahora ha sido violentísima, instantánea. Nunca en mi vida he visto a nadie [...] tan triste» (Revueltas, 1979, p. 13).

Afirma también que, para nosotros, los mexicanos, no existe el horror: de tal modo estamos acostumbrados que «Nos fascina Coatlicue. Los niños, para jugar, se ponen esas horribles máscaras de hule que, ahora me doy cuenta, no son sino [caras] de leprosos» (Revueltas, 1979, p. 19).

En las novelas de este autor, no solo en Los muros de agua, hay una buena cantidad de elementos mayas y aztecas. Puede decirse que la monstruosidad de la estatuaria indígena es una vertiente de la construcción de analogías en la prosa narrativa de José Revueltas; además de los numerosos vocablos nahuas que el lector encuentra a cada paso, en sus relatos está la deformación humana que se funde con el reino animal, característica del arte mesoamericano. Sus personajes deambulan por escenarios prehistóricos, como el archipiélago que conforman Las islas Marías, para lo cual se ven caracterizados mediante una mezcla de formas humanas y zoológicas, como en la Coatlicue, madre de Huitzilopochtli. De aquí la fascinación de los mexicanos a la que se refiere Revueltas, la mole de piedra que estuvo enterrada desde 1521, año de la caída de la México-Tenochtitlan, hasta 1790, hacia el final del Virreinato. Al quedar expuesta por una remodelación de la plaza de Armas, los indígenas comenzaron a hincarse ante ella, a llevar ofrendas, a dejar velas encendidas, como si fuera otro santo de la iglesia. Las autoridades ordenaron retirarla de la catedral y llevarla a un lugar apartado. Para el efecto, se eligió la universidad, pero los indígenas insistieron en su veneración, así que se decidió enterrarla de nuevo. Se desenterró una vez más cuando Alexander von Humboldt pidió que le permitieran verla, pero ante el fervor que suscitó de nuevo tuvo que volver a enterrarse. Un siglo después, la poderosa piedra salió a la superficie en definitiva. Dice Edmundo O'Gorman que su libro El arte de la monstruosidad no es otra cosa que el producto de la «imborrable impresión que le dejó la contemplación de la colosal estatua» y añade que «El hombre medieval hubiera encontrado afinidad en [el arte azteca] pues tienen en común [...] la fealdad, que podríamos caracterizar como lo monstruoso» (O'Gorman, 2002, p. 72).

En los personajes de Revueltas puede verse esta superposición de naturalezas que hay en la Coatlicue, donde, según O'Gorman (2002), se encuentra «una expresión consustancial de lo animal y de lo humano», como en el ya mencionado subteniente Smith de esta novela: 
Cuando todas las mañanas, entre las nueve y las diez, oían un ruido particular, un ruido a la vez elástico y seco, de ligaduras restiradas y sin lubricación, se ponían a gruñir como en un infierno, como gruñen los cerdos por cualquier cosa para demostrar su profundísimo apego a la vida. Y es que el ruido lo provocaba el subteniente Smith al encaminarse a los chiqueros moviendo sus piernas escrofulosas y sus brazos embrionarios, de animal aún no consumado (Revueltas, 1979, p. 130).

La apariencia de los personajes de Los muros de agua bien puede asociarse con las deidades prehispánicas: «la luz aquella de los cigarrillos les mordía la cara tornándola en un fragmento irreal, como si se tratase de viejos ídolos descubiertos entre la tierra» (Revueltas, 1979, p. 155). Este escritor buscaba la fealdad humana, era su predilección: indigentes, leprosos, obreros mutilados, prostitutas enfermas, enanos, homosexuales viejos, en una construcción visual y existencial de la población a la cual se puede atribuir el dolor más profundo y las más complejas existencias.

La fusión de la naturaleza animal y la humana de la mitología mexicana antigua llevó a Revueltas a la invención de símiles entre sus personajes y las serpientes, las iguanas, los batracios y los lagartos, con un procedimiento de taxónomo que reporta sus observaciones y anota con objetividad movimientos y gestos que solo pueden ser humanos, porque ningún otro animal los puede tener.

En su breve ensayo De la enfermedad, Virginia Woolf $(2014$, p. 26) escribe que «resulta en verdad extraño que la enfermedad no haya ocupado un lugar con el amor, la batalla y los celos entre los principales temas literarios». José Revueltas representa una excepción a esto que observa la autora de Una habitación propia. En su obra narrativa hay personajes tan contradictorios y enfermos que se contagian de sífilis por amor, como Gregorio hace con Epifania en Los días terrenales; otros que también se contagian de síflis para cobrar venganza de su verdugo, como la prostituta Soledad en Los muros de agua.

\section{Contribuciones}

José Martínez Torres ha participado en la concepción del artículo, en la recolección de datos, en la redacción y aprobación de la versión final.

\section{Fuente de financiamiento}

Autofinanciado.

\section{Conflictos de interés}

El autor declara no tener conflicto de interés. 


\section{REFERENCIAS BIBLIOGRÁFICAS}

Franco Ávila, D. (2006). Como un espía de Dios. Entrevista con José Revueltas. Revista de la Universidad de Chiapas, I(4), pp. 27-30.

O'Gorman, E. (2002). El arte de la monstruosidad y otros escritos. Barcelona: Planeta.

Revueltas, J. (1979). Los días terrenales. Obras completas, volumen 3. Ciudad de México: Ediciones Era.

Revueltas, J. (1979). Los muros de agua. Ciudad de México: Ediciones Era. Woolf, V. (2014). De la enfermedad. Barcelona: José J. de Olañeta.

Recibido: 21/9/2019

Aceptado: 6/11/2019 